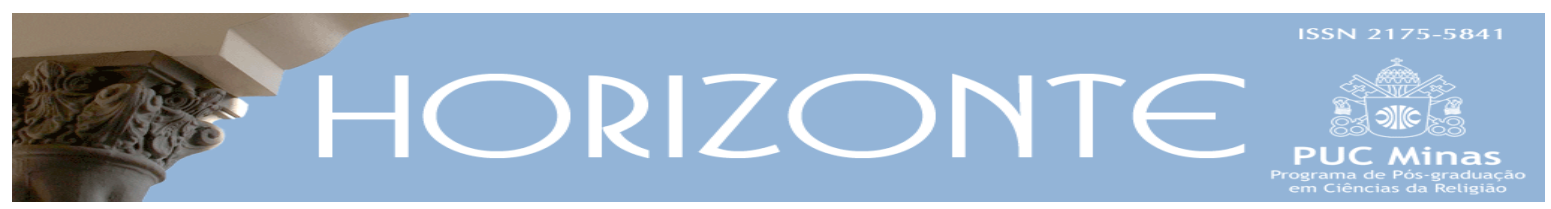

Dossiê: Fundamentalismos e Democracia - Temática Livre ๑2-

\title{
Aprendizados no campo da metodologia de orientação acadêmica
}

\author{
Learning in the field of academic supervision methodology
}

Faustino Teixeira *

\begin{abstract}
Resumo
A pesquisa acadêmica exige uma gama de procedimentos. Cada área desenvolve seus métodos, que são avaliados pelos resultados da qualidade das pesquisas. Para quem se inicia nesse processo, conhecer esses passos e procedimentos é muito significativo e definidor da formação do pesquisador. $O$ presente texto, nascido na área de Ciências da Religião e Teologia, tem por objetivo a apresentação do método que foi desenvolvido pelo autor, professor convidado do Programa de Pós-graduação em Ciência da Religião da UFJF - PPCIR-UFJF, em mais de três décadas de orientação, pesquisa e aprendizado. $\mathrm{O}$ artigo foi produzido a partir da experiência adquirida das orientações e mostra as condições fundamentais para o trabalho acadêmico, especialmente indicadas por João Batista Libanio, mas também por outros pesquisadores. A parte central do texto é a sistematização do método de orientação acadêmica denominado "método eletrônico", termo criado por Libanio, e assumido pelo autor em suas mais de cinquenta orientações. Além de indicar os passos desse método, com observações importantes e práticas, há um exemplo de aplicação sobre como elaborar um artigo.
\end{abstract}

Palavras-chave: Método acadêmico. Método eletrônico. Pesquisa. Orientação acadêmica.

\begin{abstract}
Academic research requires a range of procedures. Each area develops its methods, which are evaluated by the quality of the research results. It is very meaningful and defining for those who are beginning this process to know these steps and procedures to form a researcher. The present text, born in the Religious Studies and Theology area, aims to present the method that was developed by the author, a visiting teacher at the Graduate Program in Religious Studies at UFJF - PPCIR-UFJF, in more than three decades of orientation, research, and learning. The paper was produced from the acquired experience of the orientations and shows the fundamental conditions for academic work, especially indicated by João Batista Libanio, but also by other researchers. The main part of the text is the systematization of the academic orientation method called "electronic method", a term created by Libanio, and assumed by the author in his over fifty orientations. Besides indicating the steps of this method, with important and practical observations, there is an example of application on how to write an article.
\end{abstract}

Keywords: Academic method. Electronic method. Research. Academic orientation.

Artigo submetido em 5 de janeiro de 2021 e aprovado em 14 de dezembro de 2020.

* Doutor e Pontifícia Universidade Gregoriana (Roma). Professor convidado do PPCIR-UFJF, pesquisador do CNPq e consultor do ISERAssessoria. País de origem: Brasil. E-mail: dutiguera@gmail.com 


\section{Introdução}

Atuei por muitos anos na atividade acadêmica, desde os anos da PUC-RJ até meu ingresso na UFJF, em 1989. Tudo começou em 1978 quando ingressei no Mestrado em Teologia, sob a preciosa orientação de João Batista Libanio (19322014), que foi quem sempre me incentivou nos caminhos da formação pessoal e acadêmica. Devo muito a ele em todo o meu aprendizado. Foi ele quem me estimulou a ir para a PUC-Rio e quem me incitou a fazer o doutorado em teologia na Pontifícia Universidade Gregoriana de Roma, iniciado em 1982.

Com ele aprendi os passos essenciais da metodologia acadêmica e dos segredos da orientação acadêmica. Foi ele quem me ajudou sobremaneira a quebrar difíceis bloqueios na arte da organização e da redação. Foi a partir de seu impulso que fiquei mais leve, destemido e livre para poder ingressar nesse desafiante trabalho da exposição pública das ideias.

Tenho também que reconhecer a presença de dois outros grandes mestres na minha formação acadêmica: o meu orientador de doutorado, Félix Pastor (19332011), que pude conhecer ainda antes de ingressar na Gregoriana. Foi minha turma de mestrado que suscitou sua vinda para o ensino na PUC-Rio. Com maestria, ele ensinava um semestre no Brasil e outro em Roma, sendo responsável pela orientação de inúmeros doutores que atuam hoje na teologia no Brasil, América Latina e outros lugares do mundo. Com ele pude também aperfeiçoar o método que havia aprendido com o Libanio, curiosamente nomeado como "método eletrônico". Isso num tempo quando não havia ainda computador. Tanto minha dissertação de Mestrado na PUC-Rio como o doutorado foram redigidos em máquina de datilografia. Um trabalho extremamente difícil, sobretudo no doutorado, com uma tese de 1.100 páginas sobre a experiência das CEBs no Brasil (TEIXEIRA, 1985). ${ }^{1}$

\footnotetext{
${ }^{1}$ No Brasil, a tese foi publicada em três obras separadas: (TEIXEIRA, 1988a; 1987; 1988b). Os volumes correspondem, respectivamente, às três partes da tese.
} 
O outro professor que foi muito importante na minha orientação, que me orientou no pós-doutorado foi Jacques Dupuis (1923-2004), docente na Gregoriana. Com ele pude desenvolver a arte da liberdade, da coragem e da ousadia. Escrever sem temor, evitando autocensuras ou bloqueios de outras ordens, que deterioram a criatividade e a abertura ao mundo. Dizia sempre em sala de aula: "Não sei ensinar o que eu não penso". Esse mote me acompanha até hoje e suscitou um caminho bonito em minha reflexão, que me traz alegria, serenidade e destemor.

Recordo-me ainda da presença de outro professor em minha vida, tão importante para o apoio na esfera metodológica: Clodovis Boff. Nossa turma de Mestrado na PUC-Rio, no final da década de 1970, teve o privilégio de contar com um corpo docente de excelência, que ajudou a formar uma boa parte dos leigos que atuam hoje na teologia brasileira. Entre eles, Clodovis Boff, que tinha retornado de seu doutorado na Bélgica, sob a orientação competente de Adolphe Gesché (19282003). Sua obra Teologia e Prática (BOFF, 1978) foi objeto de um curso no Mestrado e toda a sua tessitura envolvia a questão metodológica. Certa vez, fui conversar com ele sobre o meu projeto de dissertação de Mestrado. Quando mostrei o esquema para ele, num toque de olhar, examinou o texto e deu-me um conselho certeiro: o tema estava amplo demais. Aconselhou-me a restringir-me ao primeiro capítulo, que tratava da origem das CEBs no Brasil, deixando os outros dois para um trabalho futuro no doutorado. Segui fielmente o seu conselho e assim ocorreu. São luzes que acontecem na vida acadêmica e que dependem muito dos mestres e orientadores que encontramos pelo caminho.

Em outro momento, já no doutorado, lembro-me que fui conversar com o meu orientador, Félix Pastor. Estava naquele momento meio travado na redação. Em menos de meia hora, a experiência do mestre discerniu o problema. Entrei com uma questão difícil e saí com dois capítulos definidos. Outra luz na caminhada. E assim ocorre com os que têm o privilégio de encontrar um ambiente propício de receptividade e acolhida. 
A partir desses exemplos, pude tecer o meu caminho de orientador, tendo a alegria de constatar que nunca perdi sequer um aluno no trabalho de orientação: 21 doutorados concluídos (1 em andamento), 33 mestrados e algumas supervisões de pós-doutorado. Todos concluíram com sucesso os seus trabalhos, vencendo as crises, as dificuldades, a falta de horizontes. Tudo com base numa metodologia da paciência, buscando ouvir o outro, entendendo o seu momento, aguardando a reflexão chegar no seu devido lugar. Esse é um segredo bonito. Há uma passagem num livro de Rainer Maria Rilke que me ajudou muito a entender esse processo. Ele diz:

O senhor é tão moço, tão no início de tudo, e gostaria de lhe pedir da melhor maneira possível, estimado senhor, que tenha paciência com tudo o que é insolúvel em seu coração e que tente se afeiçoar às próprias questões como quartos trancados e como livros escritos numa língua bem desconhecida. Não busque agora as respostas; não lhe podem ser dadas porque não poderiam viver. E se trata de viver tudo. Viva agora as questões. Viva-as talvez aos poucos, sem notar, até chegar à resposta um dia distante. (RILKE, 2011, p. 152).

A vida acadêmica é complexa e nem todos estão preparados para avançar em seus meandros. Há casos de pessoas que precisam ser orientadas a perseguirem outros caminhos, evitando o excessivo desgaste de uma vida que vem alimentada por uma vocação. Esse discernimento é essencial e o bom orientador percebe logo isso, e pode ajudar muito o aluno a encontrar o seu caminho.

Ter um mestre é essencial para esse crescimento pessoal. Há uma passagem clássica num livro que utilizo muito nos meus cursos sobre zen budismo, $A$ arte cavalheiresca do arqueiro zen (HERRIGEL, 1978), onde o autor relata a relação entre o discípulo e o mestre. Sinaliza que o caminho de aprendizado é áspero:

Muitas vezes, a única coisa que mantém o discípulo animado é a fé no mestre, em que só agora reconhece o domínio absoluto da arte: com sua vida dá-lhe o exemplo do que seja obra interior, e convence-o apenas com sua presença. Nessa etapa, a imitação do discípulo atinge a maturidade, conduzindo-o a compartilhar com o mestre o domínio artístico. Até onde o discípulo chegará é coisa que não preocupa o mestre. Ele apenas lhe ensina o caminho, deixando-o percorrê-lo por si mesmo, sem a companhia de ninguém. (HERRIGEL, 1978, p. 57). 
Com a leitura de Herrigel pude perceber que o trabalho decisivo não pertence unicamente a nós, mas depende da criação de um clima propício em que algo pode acontecer e revelar horizontes novidadeiros. É o que ocorre, por exemplo, na arte do tiro com arco, que para seu sucesso é necessário penetrar na dimensão "espiritual”, interior. Há que ter despojamento e despreocupação. Diz Herrigel que a natureza misteriosa do tiro com arco está no "combate do arqueiro contra ele mesmo" (HERRIGEL, 1978, p. 17). E acrescenta que o mérito do tiro não pertence ao arqueiro, pois o sucesso desse “algo" que ocorre se processa com o eu “esquecido de si mesmo e de toda intenção” (HERRIGEL, 1978, p. 63).

É uma sabedoria ancestral, como podemos igualmente perceber no pensamento de Chuang Tzu, recolhido na obra de Thomas Merton a respeito. Uma reflexão que remonta há 2.500 anos na Ásia:

\author{
Quando um arqueiro atira sem alvo nem mira \\ está com toda a sua habilidade. \\ Se atira para ganhar uma fivela de metal \\ Já fica nervoso. \\ Se atira por um prêmio em ouro \\ fica cego ou vê dois alvos - \\ está louco. \\ Sua habilidade não mudou. Mas o prêmio \\ cria nele divisões. Preocupa-se. \\ Pensa mais em ganhar \\ do que em atirar - \\ e a necessidade de vencer \\ esgota-lhe a força. (MERTON, 1977, p. 139).
}

Ainda com Rilke, aprendi algo que se relaciona profundamente com tudo o que referi aqui. $\mathrm{O}$ trabalho acadêmico profundo requer condições fundamentais, a começar pelo cuidado com o mundo interior. Em sua sétima elegia de Duíno, sublinha que o mundo só existirá "interiormente" (RILKE, 2013, p. 63). É também o conselho que ele dá ao candidato a jovem poeta:

Procure entrar em si mesmo. Investigue o motivo que o manda escrever; examine se estende suas raízes pelos recantos mais profundos de sua alma; confesse a si mesmo: morreria, se lhe fosse vedado escrever? Isto, acima de tudo, pergunte a si mesmo na hora mais tranquila da sua noite: 'Sou mesmo forçado a escrever? Escave dentro de si uma resposta profunda. (RILKE, 2013, p. 63). 
É a partir de tais pressupostos que posso apontar aqui algumas pistas que fui percebendo ao longo de minha trajetória acadêmica para ajudar no trabalho delicado de orientação dos alunos. Servir-me-ei aqui, sobretudo das agudas reflexões tecidas por João Batista Libanio em dois livros que foram lume na minha trajetória pessoal e na minha atividade de orientador acadêmico. São os livros: $A$ arte de formar-se (LIBANIO, 2001a) e Introdução à vida intelectual (LIBANIO, 2001b). Ao final, partilho algumas notas pessoais que fui passando para os meus orientandos ao longo de minha atuação aqui na UFJF, no programa de pósgraduação em ciência da religião.

\section{As condições para o trabalho acadêmico: pistas abertas por João Batista Libanio}

Em precioso livro sobre $A$ arte de formar-se (2001), João Batista Libanio levanta uma questão fundamental para aqueles que buscam ingressar com seriedade no mundo acadêmico, e sobretudo no mundo da produção escrita. Trata do que significa aprender a conhecer e a pensar. É o tema do capítulo primeiro de seu livro. Retoma a ideia de que estamos numa cultura da informação, que requer muita atenção, lucidez e capacidade de reflexão objetiva e de síntese. Estamos todos envolvidos num ciclo de informação que é impressionante. O desafio é aprender a relacionar e a contextualizar. As coisas estão aí e nos oferecem lições, que Libanio sintetiza com felicidade: as coisas e seu mundo exterior podem nos educar significativamente, desde que tenhamos um olhar lúcido sobre elas. Elas "educam-nos o sentido da observação", e esse caminho de educação passa pela tranquila observação. No processo de aprendizado das coisas é que processamos a dinâmica de modificar nossa atitude diante delas.

Na visão de Libanio, "pensar é analisar e sintetizar, separar e unir". Acionar o pensamento criativo é estar sempre em suspensão com as certezas absolutas, ou

seja, saber com clareza criar uma argúcia da desconfiança crítica permanente. Isso possibilita o acesso à complexidade do real, com suas nuances singulares. Para tanto, o caminho do desenvolvimento da capacidade de relação: 
Relacionar é superar uma visão dualista que pensa o mundo sempre divididamente entre sujeito e objeto, material e espiritual, natureza e cultura, ser humano e mundo, razão e emoção, feminino e masculino, mente e corpo, transcendência e imanência etc. Positivamente, significa articular o máximo possível entre esses polos. (LIBANIO, 2001a, p. 31).²

O pesquisador deve se dar conta de que se encontra num "mundo de incertezas", e toda a calma, paciência e discernimento devem envolver o trabalho de reflexão. O clima que deve envolver o pensar é de radical repulsa a qualquer dogmatismo e inflexibilidade na reflexão. Há que estar sempre aberto e disponível para colocar-se em questão, a todo tempo. É o caminho de situar-se num horizonte complexo. Serve também de ajuda para o pesquisador o precioso livro de Otto Maduro, Mapas para a festa (MADURO, 1994), no qual aborda reflexões latinoamericanas sobre a crise e o conhecimento.

Em livro mais específico sobre a vida intelectual, Libanio conseguiu a proeza de favorecer um guia introdutório que considero excepcional para os que buscam o trabalho acadêmico e de redação (LIBANIO, 2001b). O livro é a rota que me inspirou a escrever essas linhas do artigo, e nele me baseio. No capítulo primeiro, trata das atitudes fundamentais da vocação intelectual. Indica que diferentemente da profissão, que envolve preparação técnica, competência e eficiência, a vocação, por sua vez, "fala de decisão e realização pessoal, chamado interior, paixão, amor e gosto pelo que se faz" (LIBANIO, 2001b, p. 27). O que alimenta a vocação é a motivação e esta é essencial para os que se dirigem ao trabalho acadêmico. Há que ter motivação para o sucesso de qualquer empreitada. Vemos, com certa tristeza, que há estudantes que buscam o seu caminho na pós-graduação sem se ater devidamente a tal dispositivo, mas acabam por inserir sua pesquisa tendo em conta não a sua motivação, mas as linhas de pesquisa que estão disponíveis nos programas a cujo ingresso almejam.

Em razão disso, a escolha dos temas nem sempre se coaduna com a vocação específica do egresso, e isso produz fadiga e dispersão, quando não desânimo e desistência. É algo sério que vem ocorrendo no Brasil. E em casos de Programas

\footnotetext{
${ }^{2}$ Nesta parte estamos concentrados no capítulo primeiro de seu livro.
} 
ligados a Faculdades particulares, muitas vezes os orientadores são provocados a orientarem dissertações ou teses que extrapolam o seu campo específico de conhecimento, dificultando muito o trabalho preciso da orientação. Dentre os desafios de uma vocação intelectual está o reconhecer que o prazer pela pesquisa deve envolver o estudante integralmente, produzindo a necessária temperatura vital para o sucesso da pesquisa. É um caminho que implica "disciplina, responsabilidade, de horas de estudo, de tenacidade, de vigílias, de trabalho, de aplicação" (LIBANIO, 2001b, p. 32). Como bom jesuíta, Libanio, nos adverte que "uma vida intelectual bem regrada amadurece a personalidade" (LIBANIO, 2001b, p. 29).

Dentre as exigências de uma vocação intelectual está o firme desejo de tomar a sério a "decisão de querer pensar", e isto começa pelo árduo trabalho de leitura, "despojando-se, enquanto possível, dos preconceitos ideológicos, religiosos e dogmáticos" (LIBANIO, 2001b, p. 44). E aqui cabe o exemplo singular do pensamento de Otávio Velho (2001), que sugere uma antropologia apofática, que se despe de preconceitos intelectuais prévios, que acabam por condicionar negativamente a pesquisa. Em vez de o pesquisador atender ao campo, ele acaba por querer provar no campo a literatura prévia que marcou o seu conhecimento, tentando enquadrar a visão no conhecimento e perdendo a possibilidade de se admirar com a novidade captada no real. Otávio Velho defende uma perspectiva que se define pelo "esforço de empatia" e de aperfeiçoamento do "ouvido musical" para a religião. Adverte que o campo do estudo da religião vem demarcado por uma "absoluta impossibilidade" de manutenção de uma "postura de mera observação". O que para determinado olhar pode indicar uma limitação "nativa", revela, na realidade, a ampliação do quadro de compreensão do fenômeno analisado (VELHO, 2001, p. 233-250)3.

Não sem razão, Otávio Velho vem postulando ultimamente uma "antropologia apofática", que silencia um pouco mais a teorização e o conhecimento prévio, em favor da captação do que há de imprevisível e

\footnotetext{
${ }^{3}$ Ver também Segato (1992, p. 114-135).
} 
surpreendente no mundo do outro. Faz uma crítica ao processo crescente de escolarização em programas de pós-graduação em antropologia, onde o foco deixou de ser o trabalho de campo. Com base nos trabalhos de Tim Imgold, chama a atenção ao sempre fundamental aprendizado de "ver as coisas", de ouvi-las e sentilas de forma sempre novidadeira. Indica que "o reconhecimento do outro não pode ser apenas intelectualista e que se assim o for, corremos o risco de a nossa atividade ser atingida no que ela tem de mais precioso" (VELHO, [s.l; s.n.], [20--], p. 8$) .4$

Retomando Libanio, temos que nos dar conta de que nos inserimos num campo de superespecialização, que acaba complicando o trabalho de síntese e recolhimento do aluno, diante de um excesso de informações disponibilizadas pela internet. Saber pensar é ter sempre o pé no chão, buscando "situar os problemas, as realidades em seus contextos”. Evitar toda e qualquer unidimensionalização no trabalho reflexivo. Há que se abrir ao máximo para o mundo interdisciplinar e multidisciplinar: "Trata-se de criar um habitus mentis de nunca abordar uma questão fora do conjunto em que se situa. Numa imagem simples: nunca se dependura um cabide sem antes estender o varal” (LIBANIO, 2001b, p. 48).

Para o sucesso do trabalho, um passo decisivo é a "cultura do estudo e da leitura" e um cuidadoso trabalho de uso do tempo. O trabalho intelectual tem que ser decidido, programado e cumprido. Diz Libanio que a primeira regra é não jogar fora o tempo: "Saber tomar o tempo necessário para as ações conforme sua natureza, sem sacrificá-lo em nome de uma lógica da eficácia” (LIBANIO, 2001b, p. 58). Essa questão do tempo é de prioridade. Indica Libanio que

tem-se sempre tempo para o que é prioritário. O dia em horas igualmente para todas as pessoas. Toca-lhes dividi-lo em atividades. Para as atividades escolhidas para caber dentro de 24 horas, ter-se-á sempre tempo. Para as descartadas, não se encontra tempo. Logo o problema não é falta de tempo, mas de localização das ações no interior do quadro temporal. (LIBANIO, 2001b, p. 59).

${ }^{4}$ Ver também Velho (2005, p. 35-36). 
De forma sábia, Libanio assinala que "as atividades não requerem o mesmo tipo de energia, atenção, qualidade de empenho". Quando nos debruçamos sobre estudos mais teóricos e especulativos, a demanda é maior. Ele assevera:

Quanto mais repousada e descansada alguém tiver a mente, de quanto mais silêncio e tranquilidade dispuser, quanto mais agradável e recolhido for o ambiente, tanto mais valioso será esse tempo de estudo. Sua rentabilidade costuma ser maior. Portanto, a qualidade do tempo se mede pelas circunstâncias favoráveis ou não à atividade intelectual (LIBANIO, 2001b, p. 60).

De sua longa experiência no campo da orientação, bem como de sua presença ativa nos trabalhos de assessoria pastoral e vivencia jesuíta, Libanio guarda consigo alguns valores que são fundamentais: a honestidade como passo essencial; uma abordagem de aproximação do objeto de pesquisa de forma aberta e sem preconceito; Uma preocupação de penetrar no pensamento do outro, buscando captar sua lógica interna e suas demandas; e o cuidado decisivo de honestidade da exposição de seu pensamento, evitando distorções, plágios ou equívocos. E nesse processo dinâmico, o esforço contínuo para "reformular de diversas maneiras a mesma questão" (LIBANIO, 2001b, p. 124).

No âmbito da estruturação da questão a ser trabalhada, outros requisitos se colocam para o pretendente ao trabalho acadêmico. Trata-se de saber com clareza qual o objeto que pretende investigar ao longo do tempo estabelecido para o trabalho. É necessário encontrar, com precisão, um marco referencial. Ele é "o resultado da organização das experiências, teorias, reflexões, ideias, dos pontos de vista, práticas, valores que alguém vai acumulando durante sua história humana” (LIBANIO, 2001b, p. 125). É o momento crucial de se "captar o sentido do problema, a estrutura teórica da questão". Tudo há de convergir num "esquema claro, didático, lógico do tema, no qual as partes estejam bem articuladas entre si” (LIBANIO, 2001b, p. 124). O recurso ao dicionário é sempre essencial, inclusive para ruminar as palavras-chave que vão orientar o roteiro. Nesse campo, aconselho sempre aos alunos o precioso Dicionário analógico da língua portuguesa (AZEVEDO, 2010). É uma dica preciosa sobretudo para o momento da redação do trabalho. 
Trabalhar com alegria e empenho exige do pesquisador esse incentivo no âmbito emocional. A assimilação profunda ocorre quando os novos elementos que vão emergindo integram-se no "marco referencial da pessoa". Há que atender, de forma séria e dedicada, às condições externas de descanso. Libanio, como jesuíta regrado, sinaliza isso como essencial. Só quando o corpo colabora o trabalho encontra o clima propício para sua realização. Diz Libanio que "é fundamental manter a saúde física e psíquica, não só evitando o esgotamento como também cuidando de manter o organismo e o psiquismo sadios" (LIBANIO, 2001b, p. 130). O tempo dedicado ao descanso é indispensável: "O descanso merece grande cuidado". E a regra geral é: "O descanso se faz pelo oposto5. Cansaço físico pede repouso. Cansaço psíquico pede exercício físico”, e ele exemplifica:

As pessoas cuja atividade principal é física descansam vendo TV, filmes, lendo coisas leves que distraiam. Quem, por outro lado, empenha suas energias fundamentais nas atividades intelectuais, desopila por meio do esporte, da ginástica, do contato com a natureza, de passeios e não ficando diante da TV, da internet, fechando-se em salas de cinema ou mesmo dedicando-se a leituras de distração, ainda que tais atividades sejam mais leves do que o estudo empenhativo (LIBANIO, 2001b, p. 130).

Seguem outros conselhos importantes:

À noite, cultivar atitudes tranquilas e repousantes, como leituras de espiritualidade, dos místicos, de poetas, ou ouvir música, dar passeios gratificantes, curtir conversas agradáveis. Música barulhenta, filmes violentos e emocionais, leituras de textos difíceis, redação de trabalhos exigentes, estudos pesados são desaconselhados, em geral na parte da noite, pois afetam negativamente o descanso do sono (LIBANIO, 2001b, p. 130-131).

Os grandes místicos, como Thomas Merton, na sua experiência espiritual, louvam o cuidado com o tempo da gratuidade, essencial para propiciar o clima pessoal para o trabalho intelectual. São aparentemente contraditórios, mas se irmanam profundamente na preparação do mundo interior. Diz Merton que "não é só a ação ou a experiência que enriquecem o nosso ser. Tudo depende da qualidade dos nossos atos e experiências" (MERTON, 2003, p. 113).

\footnotetext{
${ }^{5}$ Libanio utilizava sempre a expressão per oppositum para arrolar essa importante questão.
} 
Uma forma de driblar ou vencer nossa tendência dispersiva ou desordenada, é saber encontrar as pausas fundamentais no ritmo de nosso trabalho. Sinaliza Merton que

há ocasiões, portanto, em que, para guardarmos a nossa existência, temos simplesmente de ficar sem fazer nada. E para um homem que se deixou arrastar completamente fora de si por sua atividade, nada é mais difícil do que ficar em sossego, sem fazer nada. O próprio ato de repousar é o ato mais difícil e mais corajoso que ele pode realizar: e, e muitas vezes, está acima de suas forças (MERTON, 2003, p. 114).

Diz Libanio, com acerto, que a felicidade não é resultado da intensidade, mas do equilíbrio interior. $\mathrm{E}$ isso é fundamental para o trabalho acadêmico.

Retomando o livro de Libanio, ele sinaliza ainda a atenção à dose certa de realismo para cada pessoa. Cada um tem seu estilo. No meu caso, o momento mais rico para a concentração e a escrita é o período da manhã, logo bem cedo. Outros têm experiências positivas diversas. O correto é encontrar o caminho adequado para cada um, mas buscando sempre equilibrar o trabalho com o descanso. Não sem razão, o Papa Francisco, em suas últimas reflexões tem acentuado um risco sério de nosso tempo, que é o da rapidación, do ritmo super acelerado das coisas e das pessoas que estão no trabalho. A velocidade que hoje se impõe a todos, nessa louca lógica da produtividade excessiva, "contrasta com a lentidão natural da evolução biológica" (FRANCISCO, 2015, n. 8).

Em sua obra conjunta com Déborah Danowski, o antropólogo Eduardo Viveiros de Castro faz menção ao que considera "um dos debates mais apaixonantes atualmente em curso" que gira em torno da "velocidade da história". Como "gesto barreira", indica uma perspectiva de desaceleração, visando uma "ecologia política do ralentamento" (DANOWSKI; VIVEIROS DE CASTRO, 2014, p. 148). Os italianos falam com propriedade da necessidade de uma decrescita felice.

As repercussões disso no mundo acadêmico são desastrosas. O que vemos por todo canto são discentes e docentes adoecendo diante das infindas cobranças 
de produtividade e de eficácia. As exigências dos centros de fomento, com pressões sobre os diversos Programas, são inúmeras e cada vez mais rigorosas. Os tempos urgem, são curtos, e os pesquisadores têm que se integrar na marra, com o risco de perder bolsas, financiamentos e mesmo credenciamentos no ensino. Quem sai mais prejudicado, a meu ver, é a produção acadêmica, que se torna mais pobre, superficial e sofrida, delineando um perfil de pesquisador focado apenas no seu trabalho e desinteressado na abertura relacional. Isso se vê com frequência nos congressos acadêmicos, onde os pesquisadores correm de GTs em GTs, munidos de suas pesquisas, sem ter o tempo devido para acalentar e arranjar dentro de si o espaço para a reflexão serena e desapegada.

Em seu livro, Libanio chama a atenção para outro detalhe importante, nem sempre viável em nosso tempo de acomodações mais precárias. Trata-se da questão do ambiente para o estudo. O ambiente geral é essencial. Buscar uma atmosfera tranquila, que seja um incentivo de animação e empenho. A atmosfera deve entrar a favor. Ajuda muito manter aceso um circuito positivo de relações humanas, de amizade, o que enriquece o tônus sadio para o trabalho. É o que Peter Berger chama com acerto de "estruturas de plausibilidade" e um "aparelho conversacional" ativo (BERGER, 1997, p. 65-69). Criar tais atitudes de apoio constitui caminho seguro para aumentar o rendimento dos estudos.

Os orientadores da pesquisa devem atender a um dado muito importante no trabalho de contato com discentes. Ajudá-los a compreender que a produção literária é um "fator fundamental de personalidade". Isto pode ajudar ou inibir a atividade criativa. Indica Libanio que

uma vez que alguém se aventure no mundo das publicações, cai imediatamente sob possíveis críticas, quer quanto a suas ideias, quer quanto à sua maneira de escrever. Pessoas inseguras, perfeccionistas, obsessivas, rigoristas têm enorme dificuldade de escrever e publicar seus escritos. Nunca os julgam suficientemente bons para tal. Temem o mínimo sinal de rejeição, que pode ser sentido na crítica. Psicanalistas alertam-nos para o enorme temor que o ser humano tem de ser rejeitado. Prefere então nunca escrever nem publicar nada, como medo de ser criticado. Escrever, portanto, antes de tudo é um fator de personalidade (LIBANIO, 2001b, p. 164). 
Outra dica preciosa vem de Michel Beaud, no seu livro: Arte da tese (BEAUD, 1994). O autor assinala que toda produção intelectual tem que preservar o mínimo de encantamento e gratuidade. Deve nascer do coração, com motivação forte. Imaginar que o tema escolhido terá que motivá-lo por muitos anos, e que vai fixar-se na pele como uma tatuagem BEAUD, 1994, p. 25). Fundamental, igualmente, é saber escolher o orientador da pesquisa. Deve ser alguém dotado de capacidade, sensibilidade e estratégia bem definidas para ajudar o aluno a vencer as diversas barreiras que enfrentará ao longo de sua via. $\mathrm{O}$ orientador é um elemento essencial para o sucesso de um trabalho: alguém que "enfaticamente influenciará, marcará, facilitará ou atrapalhará” o início da carreira de um profissional da área.

O autor lembra ainda outro dado bem significativo, que também aprendi com meus orientadores: a escolha do assunto. Ele "não deve ser nem tão amplo que não se consiga abarcá-lo com pertinência, nem tão restrito que não tenha substância, arriscando-se a uma prolixidade vazia" (BEAUD, 1994, p. 167). Pela minha experiência no campo, sempre orientei meus alunos a trabalharem um tema num autor. É bem mais simples e plausível para a execução de um tema.

Igualmente Umberto Eco, no seu clássico trabalho, Como se faz uma tese (ECO, 2010), assinala que uma boa tese se constrói na dinâmica de interação profunda com o orientador do trabalho. A escrita de uma tese é um "exercício de comunicação”, num processo de interação, abertura e aprendizado. O estudante que se propõe a apresentar um projeto de dissertação ou tese deve estar bem consciente do horizonte que tem pela frente. Como diz Umberto Eco, "quem quer fazer uma tese deve fazer uma tese que esteja à altura de fazer”. Há que saber colocar claramente o problema inicial, e se acercar das condições para a realização do pretendido. E não esquecer da questão das línguas exigidas pelos Programas para a realização da pesquisa. Daí a importância de estar atento para os requisitos linguísticos que o tema apresentado vai exigir do candidato. Muitas vezes escolhese o tema, que implica utilização de recursos linguísticos complexos, sem se dar conta dos riscos que estão implicados. 
Outro grande pesquisador nesse campo da metodologia, Ciro Flamarion Cardoso, indicou caminhos pertinentes para a execução de projetos acadêmicos num artigo precioso, publicado pela Universidade Federal Fluminense: Como elaborar um projeto de pesquisa (CARDOSO, 20--). Dentre os critérios que presidem a escolha de um tema ele enumera o critério de relevância, o critério de viabilidade e o critério de originalidade. Enumera também os elementos que devem estar presentes num projeto sério: a identificação do problema, os objetivos propostos, as hipóteses de trabalho, o quadro teórico, as fontes e metodologia, o cronograma de execução e o referencial bibliográfico.

Na obra de Libanio, há os passos que devem marcar a estruturação do trabalho acadêmico. Indica que o trabalho deve obedecer a regras estruturais, com lógica interna bem delimitada e definida. É o desafio de superar um conhecimento mais genérico para um conhecimento elaborado e sistemático. Apresento aqui em forma pontual alguns dos passos que ele indica para a elaboração de um tema ou projeto:

- estabelecer um quadro maior da problemática;

- criar um nexo ou relação com uma questão imediatamente anterior e com a seguinte;

- definir os conceitos;

- definir o problema específico. (LIBANIO, 2001b, p. 203- 206).

Em seguida ocorre o desenvolvimento do trabalho, dando-se conta das consequências envolvidas no processo. $O$ trabalho se enriquece também quando se apontam alguns problemas conexos e já se consegue prever as objeções que poderão surgir pelo caminho. E nunca se esquecer de distribuir bem o tempo para o trabalho concreto (LIBANIO, 2001b, p. 201-202).

Num dos capítulos finais de seu livro, Libanio aborda propriamente a questão da confecção do trabalho, com pistas importantes, envolvendo os aspectos epistemológicos e didáticos. Chama a atenção para o rigor do trabalho científico, a qualidade do trabalho, a correção da linguagem. Indica que o estudante deve 
demonstrar "que percebeu bem e conhece o assunto e sabe formulá-lo de modo pessoal e próprio. A originalidade não consiste tanto na ideia nunca antes dita, mas muito na maneira peculiar de organizar o tema" (LIBANIO, 2001b, p. 223). Insiste para que o texto apresentado seja "conciso, enxuto, sem divagações ou repetições". E não ter temor ou receio de cortar todo e qualquer excesso. O que vale é a "lei da economia das palavras".

Como conselho, indica a importância de começar sempre pelo texto, deixando a introdução e a conclusão para o final, mas sempre tendo por perto o esquema geral definido com anterioridade. E que cada parte do trabalho guarde entre si uma progressividade. Há que manter um fio condutor seguro. Deve-se buscar também uma linguagem e estilo agradáveis (LIBANIO, 2001b, p. 221-226). Assegurar a consciência de que o trabalho não é fixo, mas aberto a contínuas mudanças e transformações, que devem estar previstas. São preciosos os conselhos dados por Libanio para a redação da introdução e conclusão do trabalho, e vale a pena se concentrar sobre eles no momento final do trabalho (LIBANIO, 2001b, p. 230-231).

\section{0 método eletrônico}

Com base no meu trabalho de orientação, ao longo de mais de três décadas, da PUC-Rio à UFJF, elaborei um esquema sucinto para ajudar meus orientandos no trabalho de elaboração do projeto de pesquisa. O objetivo proposto, sempre em conversa com as turmas de orientação, foi de encontrar um esquema de trabalho. Sempre considerei o sumário das dissertações e teses como o esqueleto central do trabalho a ser desenvolvido. Para facilitar o debate, tive como hábito regular de encontrar-me mensalmente com todos os meus orientandos do período para discutirmos os passos das pesquisas de cada um. Esse foi um segredo capital para o sucesso no trabalho de orientação. Fui compensado pela pronta seriedade de todos, que nunca deixaram de participar das reuniões para discutir as questões da redação de cada um. 
Ao longo de minha experiência, busquei elaborar um esquema de ajuda para a turma, com as dicas que fui captando no processo de comunicação e orientação. Decidi deixar o esquema como foi sempre apresentado a eles, sem maiores desenvolvimentos. Defini os seguintes passos:

1) Montar o quadro referencial bibliográfico: dois tipos de procedimentos

a) Elaborar uma bibliografia por ordem de chegada

b) Elaborar o fichário definitivo da bibliografia em ordem alfabética

Indico aos alunos trabalharem com folhas de cor distinta para a elaboração dessas duas bibliografias. Quando falo em ordem de chegada, quero dizer o seguinte. Na medida que o aluno vai encontrando um artigo, texto, livro ou capítulo de livro que vai utilizar no trabalho, ele vai acrescentando na página, sem preocupação de ordem alfabética, mas numerando a ordem de chegada do texto. Simultaneamente, em outra página, vai elaborando a bibliografia em ordem alfabética, que facilitará muito a montagem do referencial bibliográfico utilizado no trabalho.

2) Esquema provisório da pesquisa.

Após um certo domínio de leitura sobre o tema escolhido, o pesquisador já pode elaborar um esquema provisório da dissertação ou tese. É um passo dos mais complexos, exigindo dos estudantes muita concentração e determinação. Por minha experiência no campo, pude verificar que para ganhar sua forma "definitiva", deve-se passar por várias experimentações. Tive caso de estudantes que chegaram a propor mais de 30 roteiros diferentes, até poder encontrar o definitivo. E aconselho cada aluno a guardar a memória desse trabalho, para se dar conta da evolução adquirida. 


\section{A estruturação do Sumário:}

Introdução (1)

$1 \ldots .$.

1.1. (3)

1.2. （5）

1.3. (7)

$2 \ldots$

2.1. (9)

2.2. (11)

2.3 (13)

$3 \cdots$

3.1. (15)

$3.2 \quad$ (17)

$3 \cdot 3 \quad$ (19)

Conclusão (21)

O esquema apresentado como exemplo segue, em geral, o sumário de uma dissertação de Mestrado, com três capítulos. Para cada item do sumário indica-se um número, o que está entre parênteses ao lado do tópico preciso. Enumera-se então os diversos tópicos com números ímpares de forma a possibilitar a inserção de um novo número (par), caso seja necessário, em razão do desenvolvimento do trabalho, como a inclusão de outro tópico. O ideal é que a numeração seja feita de dois em dois números, como no quadro acima. E que esse esquema possa ser o definitivo, para não se perder o aproveitamento da leitura feita até então. 
3) Montar pastas para cada tópico.

Uma vez procedido o esquema, montar pastas para cada item, com a indicação precisa na capa da pasta sobre o tema a ser trabalhado, e o período previsto para a sua redação. Cada item do sumário se transforma numa pasta, que pode ser um envelope pardo ou de outra cor, onde as referências bibliográficas referentes àquele determinado ponto estarão inseridas. Em cada pasta serão anexadas as folhas com a indicação precisa da fonte relacionada ao tema em questão, utilizando-se o nome dos autores trabalhados, o código da bibliografia de chegada, com a referência das páginas onde a questão vem situada. No caso exemplificado, teremos 11 pastas, já incluindo aquelas que são referentes à introdução e à conclusão.

Com o tempo o pesquisador vai saber de memória a que tema relaciona tal número do código do esquema utilizado. Esse número poderá ser afixado a lápis nos próprios textos ou livros trabalhados, de forma a facilitar a pesquisa. Por exemplo, se ao ler determinado livro o pesquisador reconhece que o tema tem a ver com determinado item do sumário, ele numera a lápis no próprio livro o número que está na numeração (veja o número entre parênteses), para depois ser recolhido, mediante fotocópia ou anotação, com o acréscimo na pasta correspondente. Para facilitar o trabalho das pastas, é conveniente ampliar o esquema de cada pasta com a indicação precisa do conteúdo contido na página indicada. Isso pode acontecer mediante uma síntese do próprio pesquisador ou mesmo se utilizando do recurso de fotocópia da página mencionada. E manter viva a atenção para o modo como a citação vem inserida. Se for literal, manter sempre as aspas. Se for um breve resumo feito pelo pesquisador, será necessário voltar à fonte indicada para fazer a citação correta.

Com o tempo as pastas vão ganhando aos poucos um conteúdo teórico significativo. Quando elas estão cheias, significa que o tema tem plausibilidade. Quando não há conteúdo nas pastas, ou ele é muito precário, ou significa que o tema não tem pertinência. Pode também ocorrer que uma determinada página 
tenha muito material, isso pode ser um indicativo da necessidade de subdividir o tema, criando-se nova pasta, que indica um novo item, a ser acrescentado no sumário (número par). $\mathrm{O}$ fato de numerar deixando a possibilidade de uma nova inserção de número ajuda muito.

\section{4) A redação}

A partir daí se dá o início ao processo redacional: cada pasta vai, na verdade, significar um artigo a ser redigido. Quando se dá início à redação, o conteúdo das outras pastas cai no esquecimento. O pesquisador vai concentrar toda a sua atenção e energia na elaboração da redação da pasta em questão. Aconselho aos pesquisadores de fazer várias leituras do conteúdo da pasta e depois numerar todos os itens, em ordem crescente, num fichamento extenso, que demanda tempo, mas que será recompensado pela facilidade posterior de redação.

Em seguida, vem o difícil exercício de encontrar eixos fundamentais no conteúdo descrito, e em torno deles reunir as citações que vão nessa mesma linha. Ou seja, trata-se agora de organizar os eixos que vão formar os vários parágrafos ou partes do artigo. Uma vez definidos os eixos, agora é concentrar-se para encontrar a melhor distribuição dos temas em ordem progressiva de compreensão, para que a redação tenha uma progressividade.

5) Esquema de elaboração de um artigo

Para facilitar ainda mais a compreensão, sintetizo um exercício de elaboração de um artigo (que no caso pode ser uma parte do esquema já elaborado pelo pesquisador):

a. Captar o material bibliográfico relacionado ao tema a ser desenvolvido (livros e artigos).

b. Fazer um preciso fichamento de todo o material bibliográfico relacionado ao tema, tanto nos livros como nos artigos. 
c. Criar frases que resumam os conteúdos, sempre iniciadas com um ponto, que será depois numerado. Evitar frases muito longas. O ideal é não ultrapassarem duas linhas. Ao final de cada frase é necessário indicar de forma precisa o livro ou artigo citado e a página de referência.

d. Uma vez realizado o fichamento, que leva tempo e exige paciência, fazer várias leituras das folhas até encontrar temas chaves que sirvam para a elaboração do esquema de trabalho.

e. Depois de nuclear os vários temas, definir de forma clara a sua ordem, de forma que favoreça um bom encaminhamento da redação.

Para facilitar o entendimento dos leitores partilho aqui um exercício preciso de gestação de um artigo que escrevi sobre Ernesto Cardenal. Isso para favorecer a visualização do processo que rege a redação de um determinado texto.

\section{Visualização do processo de elaboração do artigo:}

Artigo: O Cântico Espiritual de Ernesto Cardenal ${ }^{6}$

Referências:

1. Luce López-Baralt. El cántico místico de Ernesto Cardenal. Madrid: Trotta, 2012.

2. Sylma García González. "Yo tuve una cosa con él y no es un concepto". Madrid/Frankfurt am Main: Iberoamericana/Vervuert, 2011.

3. Ariana Fabbri. "Y son cosas que los que se aman se dicen en la cama". La poesia mística de Ernesto Cardenal. Tesi dottorale. Università di Bologna, 2007.

4. Maria Enrica Castiglioni. Para qé metáforas? La poetica de Ernesto Cardenal

5. Teófilo Cabestrero. Ministros de Deus, ministros do povo. Petrópolis: Vozes, 1983.

${ }^{6}$ Esse era o nome inicial. Depois modificou-se. Aliás, o nome do artigo vem sempre por último. Faça sempre um nome provisório, que depois sofre aperfeiçoamento. 
6. Ernesto Cardenal. La santidade de la revolucion. Salamanca: Sigueme, 1976.

7. Ernesto Cardenal. O evangelho de Solentiname. Madrid: Trotta, 2006.

8. Ernesto Cardenal. Vida Perdida. Memorias 1. Madrid: Trotta, 2005.

9. Ernesto Cardenal. Las ínsulas extrañas. Memorias 2. Madrid: Trotta, 2002

10. Ernesto Cardenal. La revolución perdida. Memorias 3. Madrid: Trotta, 2004

11. Thomas Merton \& Ernesto Cardenal. Correspondência (1959-1968). Madrid: Trotta, 2003.

Fichamento dos textos, segundo os temas relacionados:

1. Luce López-Baralt. El cántico místico de Ernesto Cardenal. Madrid: Trotta, 2012.

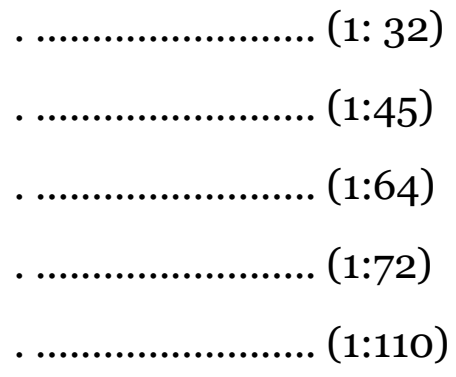

2. Sylma García González. "Yo tuve una cosa con él y no es un concepto". Madrid/Frankfurt am Main: Iberoamericana/Vervuert, 2011.

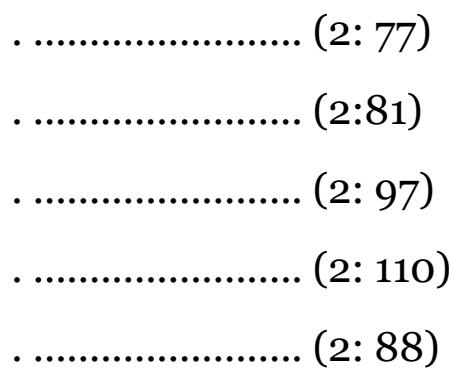

Depois de feito o fichamento geral, a atenção se volta para a nucleação dos eixos que vão possibilitar a reunião dos itens que se relacionam com o tema em questão. Essa nucleação vai favorecer o processo de construção do artigo. Os eixos 
deverão estar inseridos num esquema que garante sua progressividade e lógica interna. Exemplifico abaixo:

1. Sua importância como místico

. Cardenal, um místico em sentido estrito da palavra (1:25)

- A crítica, em geral, deixa de lado essa dimensão estritamente mística de Cardenal (1:12)

. E essa dimensão mística vem suscitando hoje um crescente interesse na crítica (1:12-13)

. O crescente interesse da crítica nesta perspectiva mística de Cardenal (2:9)

2. A especificidade da experiência mística

. A inefabilidade essencial da experiência mística (1:26)

- As experiências místicas como “caprichos de Deus”, acessíveis também àqueles que não são santos (1:15)

- As características fundamentais da experiência mística: sua essência inefável, sua qualidade noética e seu traço efêmero (1:32)

. O místico e a limitada força da linguagem humana (2:16).

3. Traços de sua biografia

. Uma biografia de Cardenal (4:122s)

. Formação acadêmica (2:36)

. Cardenal na Universidade (2:35)

. Na Universidade de Columbia (8:45)

. A continuidade dos estudos sacerdotais no México e Colômbia (2:42)

Abaixo temos outros eixos que foram escolhidos e que seguiram a mesma dinâmica dos anteriores que exemplifiquei.

4. Obras publicadas

5. A experiência da conversão

6. Sua vida na Trapa 
7. O influxo de Merton e a convivência com Merton

8. A fundação de Solentiname

9. Sua incursão na luta política

10. Sua retomada da reflexão sobre a mística

11. Uma experiência erotizada de Deus

12. Extras

É um esquema simples, prático, sistemático e que ajuda muito o pesquisador no processo da investigação e na redação do artigo.

\section{Conclusão}

Ainda que de forma bem sintética, busquei apresentar pela primeira vez, depois de tantos anos, o método de trabalho que marcou meus anos de atividade acadêmica. Nunca tinha feito isso de forma mais sistemática, embora os orientandos que passaram por meu caminho tenham conseguido captar muito bem esse método, cada qual fazendo suas inserções criativas e modificações peculiares. E tudo deu muito certo. Reconheço com grande alegria que os frutos dessa opção metodológica foram alvissareiros, e posso verificar no caminho seguido por meus orientandos as marcas positivas desse longo empenho. Daí ter resolvido deixar por escrito algo a respeito, para servir de ajuda ou apoio a outros que pretendem seguir esse belo caminho de vida.

\section{REFERÊNCIAS}

AZEVEDO, Francisco Ferreira dos Santos. Dicionário analógico da língua portuguesa. 2. ed. Rio de Janeiro: Lexikon, 2010.

BEAUD, Michael. Arte da tese. Rio de Janeiro: Bertand do Brasil, 1994.

BERGER, Peter L. Rumor de anjos: a sociedade moderna e a redescoberta do sobrenatural. 2. ed. Petrópolis: Vozes, 1997. 
BOFF, Clodovis. Teologia e prática: teologia do político e suas mediações. Petrópolis: Vozes, 1978.

CARDOSO, Ciro Flamarion S. Como elaborar um projeto de pesquisa. Programa de Pós-Graduação em História UFF-PPGH. [20--]. Disponível em: https://www.historia.uff.br/stricto/files/CARDOSO_Ciro_Como_elaborar_projeto_pesq uisa.pdf . Acesso em: 25 dez. 2020.

DANOWSKI, Débora; VIVEIROS DE CASTRO, Eduardo. Há mundo por vir? Ensaio sobre os medos e os fins. Florianópolis: Cultura e Barbárie; São Paulo: ISA, 2014.

ECO, Umberto. Como se faz uma tese. 23. ed. São Paulo: Perspectiva, 2010.

FRANCISCO, Papa. Carta encíclica Laudato si: sobre o cuidado da casa comum. São Paulo: Paulinas, 2015.

HERRIGEL, Eugen. A arte cavalheiresca do arqueiro zen. São Paulo: Pensamento, 1978.

LIBANIO, João Batista. A arte de formar-se. São Paulo Loyola, 2001a.

LIBANIO, João Batista. Introdução à vida intelectual. São Paulo: Loyola, 2001b.

MADURO, Otto. Mapas para a festa: reflexões latino-americanas sobre a crise e o conhecimento. Petrópolis: Vozes, 1994.

MERTON, Thomas. A via de Chuang Tzu. 3. ed. Petrópolis: Vozes, 1977.

MERTON, Thomas. Algum homem é uma ilha. Campinas: Verus, 2003.

RILKE, Rainer Maria. A melodia das coisas. Contos, ensaios, cartas. 2. ed. São Paulo: Estação Liberdade, 2011.

RILKE, Rainer Maria. Cartas a um jovem poeta. A canção de amor e de morte do portaestandarte Cristovão Rilke. 4. ed. São Paulo: Biblioteca Azul, 2013.

RILKE, Rainer Maria. Elegias de Duíno. 6. ed. São Paulo: Biblioteca Azul, 2013.

SEGATO, Rita. Um paradoxo do relativismo: o discurso racional da antropologia.

Religião e Sociedade, Rio de Janeiro, v. 16, n. 1-2, p. 114-135, 1992.

TEIXEIRA, Faustino. A fé na vida: um estudo teológico-pastoral sobre a experiência das Comunidades Eclesiais de Base no Brasil. São Paulo: Loyola, 1987.

TEIXEIRA, Faustino. A fé na vida: um estudo teológico-pastoral sobre a experiência das CEBs no Brasil. Tese (Doutorado em Teologia) - Pontifícia Universidade Gregoriana, Roma, 1985. 
TEIXEIRA, Faustino. A gênese das CEBs no Brasil: elementos explicativos. São Paulo: Paulinas, 1988a.

TEIXEIRA, Faustino. Comunidades Eclesiais de Base: bases teológicas. Petrópolis: Vozes, $1988 \mathrm{~b}$.

VELHO, Otávio. O que a religião pode fazer pelas ciências sociais? In: TEIXEIRA, Faustino (org.). A (s) ciência (s) da religião no Brasil. São Paulo: Paulinas, 2001. p. 233-250.

VELHO, Otávio. Trajetórias e diversidade: um caso brasileiro. [s.l; s.n.], [20--].

Mimeo, p. 8.

VELHO, Otávio. Uma antropologia apofática. Uma entrevista exclusiva com o antropólogo Otávio Velho. IHU Online, São Leopoldo, p. 35-36, 17 out. 2005. Disponível em: http://www.ihuonline.unisinos.br/media/pdf/IHUOnlineEdicao16o.pdf. Acesso em: 25 dez. 2020. 